\title{
Cost Deviation in Road Construction Projects: The Case of Palestine
}

Ibrahim Mahamid and Amund Bruland, (Norges Teknisk-Narurvitenskapelige

Universitet, Norway)

\begin{abstract}
This paper investigates the statistical relationship between actual and estimated cost of road construction projects using data from road construction projects awarded in the West Bank in Palestine over the years 2004-2008. The study is based on a sample of 169 road construction projects. Regression models based on this data, reveal that $100 \%$ of projects suffer from cost deviation: $76 \%$ of projects are under-estimated while $24 \%$ are overestimated. The deviation between estimated and actual cost average $14.6 \%$, ranging from $39 \%$ to $98 \%$. The results show that the relationship between the project size (length and width of road) and the cost deviation is very weak, the coefficient of determination $R^{2}=$ 0.0028 .
\end{abstract}

Keywords: Cost deviation, Road construction, Over-estimation, Under-estimation, Overrun

\section{Introduction}

"The construction industry has its own characteristics that distinguish it from other sectors of the economy. It is fragmented, sensitive to changing variables such as political and environmental factors, and has a significantly high rate of business failure" (Nega, 2008).

The iron triangle (cost, time, and quality) is used to measure the project performance and success. Generally, the success measure for a project is defined by completing it within specified cost, time and quality. However, the construction industry is full of projects that were completed with significant cost deviation (Amhel et al., 2010). Cost deviation is simply defined as a difference between the final cost of the project and the contract amount without any changes to the original contract.

In Palestine, the construction industry is one of the main economic driving sectors, supporting the economy. It contributes to $26 \%$ of the Palestinian GDP (MAP, 2002). It also plays a basic role in providing homes, public facilities and infrastructure, absorbing work forces and in improving the West Bank economy as a whole. However, many local construction projects report poor performance in cost and time due to causes that include: unavailability of materials, frequent amendments of design and drawings, poor coordination among participants, ineffective monitoring and feedback, lack of project leadership skills (UNRWA, 2006).

This paper presents the statistical relationship between actual and estimated cost of road construction projects using data from road construction projects awarded in the West Bank in Palestine over the years 2004-2008. The study is based on a sample of 169 road construction projects.

\section{Objectives}

The objectives of this study are:

- To reveal the magnitude and direction of cost deviation in road construction projects awarded in the West Bank over the years 2004 to 2008 based on the collected data

- To assess the relationship between the estimated and actual cost 
- To address the relation between the cost deviation and the project size (i.e. road length and road width)

\section{Relevant Past Studies}

Many studies have been conducted to investigate cost deviation in construction projects. Pickrell (1990) conducted a study for the US Department of Transportation covering US rail transit projects with a total value of $£ 15.5$ billion. The total cost overrun for eight projects was calculated to be $61 \%$, ranging from -10 to $+106 \%$.

Battaineh (1999) evaluated the progress reports of 164 building and 28 highway projects constructed during the period 1996-1999 in Jordan. He found that delays were extensive: the average overrun of actual completion time to the planned contract duration was $160 \%$ for road construction projects and $120 \%$ for building projects.

Odeck (2004) investigated the statistical relationship between actual and estimated costs of road construction using data from Norwegian road construction over the years 1992-1995. His findings revealed a discrepancy between estimated and actual costs, with a mean cost overrun of $7.9 \%$ ranging from $-59 \%$ to $+183 \%$. In absolute terms, cost overruns amounted to a formidable 519 million Norwegian kroner. One particular finding was that cost overruns appear to be more predominant among smaller projects as compared to larger ones. He also concluded that the size of cost overruns was influenced by completion time of the projects and the regions where projects were situated.

Al-Zarooni et al. (2000) conducted a survey to investigate variations in UAE public projects' estimates. They found that the variations (positive or negative) between feasibility and contract cost, ranging between $-28.5 \%$ and $+36 \%$. They stated that these variations could be explained by the fact that feasibility estimates in the government agencies are usually budgeted using a Single Unit Estimating (cost per square foot) basis, regardless of the nature of projects and their associated risks or the construction complexity of each building type. And it may also be because feasibility studies are normally done before any details are settled.

Flyvbjerg et al. (2003) conducted a study of 258 transportation infrastructure projects. The distribution of the projects was as follows: rail: 58 , fixed link (bridges and tunnels): 33 , and road: 167 projects. The projects were located in 20 nations on 5 continents, including both developed and developing nations. The geographical distribution of projects was: Europe: 181, North America: 61, and other: 16 projects. The main findings from the study are as follows:

1. 9 out of 10 transport infrastructure projects experienced cost deviation.

2. For rail the average cost deviation was $45 \%$.

3. For fixed links (tunnels and bridges) the average cost deviation was $34 \%$.

4. For roads the average cost deviation was $20 \%$.

5. For all project types the average cost deviation was $28 \%$.

6. Cost deviation exists across 20 nations and 5 continents; it appears to be a global phenomenon.

7. Cost deviation appears to be more pronounced in developing nations than in North America and Europe.

8. Cost deviation has not decreased over the past 70 years.

Cost and time overruns are common in infrastructure and building construction projects. Researches on construction projects in some developing countries indicate that by the time a project is completed, the actual cost exceeds the original contract price by about $30 \%$ (AlMomani, 1996). 
Mahamid (2011) investigated the statistical relationship between actual and estimated cost of road construction activities based on a sample of 100 road construction projects awarded in the West Bank in Palestine. The findings revealed that the average cost deviation in the investigated activities is as follows: earthworks $=-15.7 \%$, base works $=12.9 \%$, asphalt works $=18.5 \%$ and furniture works $=36.4 \%$.

A study by Skamris et al. (1996) compared the accuracy of traffic forecasts and cost estimates on large transport projects in Denmark. The main conclusion from this study is that cost overruns of $50-100 \%$ are common for larger transport infrastructure projects and that overruns above $100 \%$ are not unusual.

Jahren et al. (1990) conducted research on predictors of cost overrun rates. The analysis included 1,576 Navy construction projects that were in progress from 1984 to 1987. It was found that the shape of the frequency distribution for the cost-overrun rates changed with the size of the project. Cost overruns occurred more frequently for larger projects.

Studies have shown that the size of a construction project (contract amount) influences the rate of cost deviation. Randolph et al. (1987) found that cost overrun rates decreased as the contract amount increased based on their study for contract costs in Lansing, Michigan. While Rowland (1981), in a study of Southern United States construction contracts, found that cost overrun rates increased with increase in the contract amount of construction projects.

\section{Research Methodology}

After establishing the objectives of the study, the needed data to achieve these objectives were collected from the West Bank in Palestine. The data analysis includes regression analysis, t-test, and statistical modeling.

Based on the collected data, the discrepancies between actual and estimated cost were studied and used to derive the magnitude and direction of the ratio $\lambda$ of divergence defined as:

$$
\lambda_{i}=((\kappa-\varepsilon) / \varepsilon)_{i} \quad i=1 \ldots n
$$

Where $\mathrm{K}$ is the actual cost and $\varepsilon$ is the estimated cost.

\section{Data Collection}

To investigate the cost deviation in construction projects, extensive historical data are required. The data were collected from contracts awarded by the Palestinian agencies who are the clients of road construction projects in the West Bank. The data collected comprised 169 projects awarded over the years 2004-2008. The data were tabulated to ensure that all costs were considered, none is double-counted and all are clearly defined.

All the data were deflated to 2008 using the construction cost index from the Palestinian Economic Council for Development and Reconstruction (PECDAR). Table 1 shows the index values over the years 2004-2008, the base year is 2008 (construction index $=1$ ).

\begin{tabular}{|l|c|c|c|c|c|}
\hline Year & 2004 & 2005 & 2006 & 2007 & 2008 \\
\hline Cost index & 0,60 & 0,62 & 0,66 & 0,88 & 1 \\
\hline
\end{tabular}

Table 1 Construction cost index value in the West Bank

The collected data were classified based on their cost according to Table 2. 


\begin{tabular}{|c|c|}
\hline Classification & Category \\
\hline$<\$ 70000$ & very small project \\
\hline$\$ 70000-\$ 150000$ & small project \\
\hline$\$ 150000-\$ 300000$ & medium project \\
\hline$>\$ 300000$ & large project \\
\hline
\end{tabular}

Table 2 Classification of road construction projects in West Bank (PECDAR, 2009)

Attention was paid to the following points during data collection:

\section{Distribution of Years Awarded}

A consideration was taken to include approximately equal numbers of projects for each year over the sample period. During 2004, the effects of the second Intifada were still there, hence a low number of projects awarded during this year. The following table shows the distribution of projects in the collected data.

\begin{tabular}{|c|c|}
\hline Award year & \# of projects \\
\hline 2004 & 9 \\
\hline 2005 & 34 \\
\hline 2006 & 39 \\
\hline 2007 & 42 \\
\hline 2008 & 45 \\
\hline
\end{tabular}

Table 3 Projects number vs. year awarded in the collected data

\section{Project Size}

A consideration was taken to include an approximately equal number of each projects size. The following table shows the distribution of projects sizes. It should be noted that there are comparatively few very small projects awarded in the West Bank.

\begin{tabular}{|c|c|}
\hline Project size & \# of projects \\
\hline very small & 20 \\
\hline small & 46 \\
\hline medium & 48 \\
\hline large & 55 \\
\hline
\end{tabular}

Table 4 Projects distribution based on size.

\section{Model Development}

Previous studies show different methods used to study the relation between the construction cost and factors believed to influence construction costs. Regression models are widely used in these studies. They are effective due to a well-defined mathematical approach, as well as being able to explain the significance of each variable and the relationships between independent variables (Sodikov, 2005). These models with their relational structures are expected to provide reliable long-term estimates (Wilmot and Cheng, 2003). The developed models in this study are of this type. Once the variables to be included in the proposed models have been identified, a series of models were developed. 


\section{Results and Discussion}

\section{Analysis of Cost Deviation}

- For the collected data of 169 road construction projects, a statistical analysis shows the following results:

- $100 \%$ of projects suffer from cost deviation

- 129 projects out of 169 projects $(76.33 \%)$ have cost under-estimates

- 40 projects out of 169 projects (23.67\%) have cost over-estimates

- The average cost under-estimate is $22.34 \%$ ranging from $0.39 \%$ to $98.04 \%$

- The average cost over-estimate is $-10.54 \%$ ranging from $-39.27 \%$ to $-0.17 \%$

- The average cost deviation in all projects is $14.56 \%$, this is calculated by taking the arithmetic average of cost deviation percentages of all projects

- The total cost deviation in percent is $6.67 \%$, this is calculated by dividing the sum of cost deviation of all projects over the sum of estimated cost of all projects

\section{Classification of Cost Deviation in Road Construction Projects}

The following charts show the frequencies of cost over and under estimation in total cost of 169 road construction projects.

Figure 1 shows the S-curve of cost under estimation in road construction projects. It shows the accumulative frequency of 129 projects with cost under-estimates. Knowing that the contracts accept $\pm 10 \%$ cost diverge, it can be concluded from the figure that $70 \%$ of the projects have critical cost under-estimates ranging from $10 \%$ to $100 \%$. This means that most of projects suffer from fund shortage which is problematic to all construction parties.

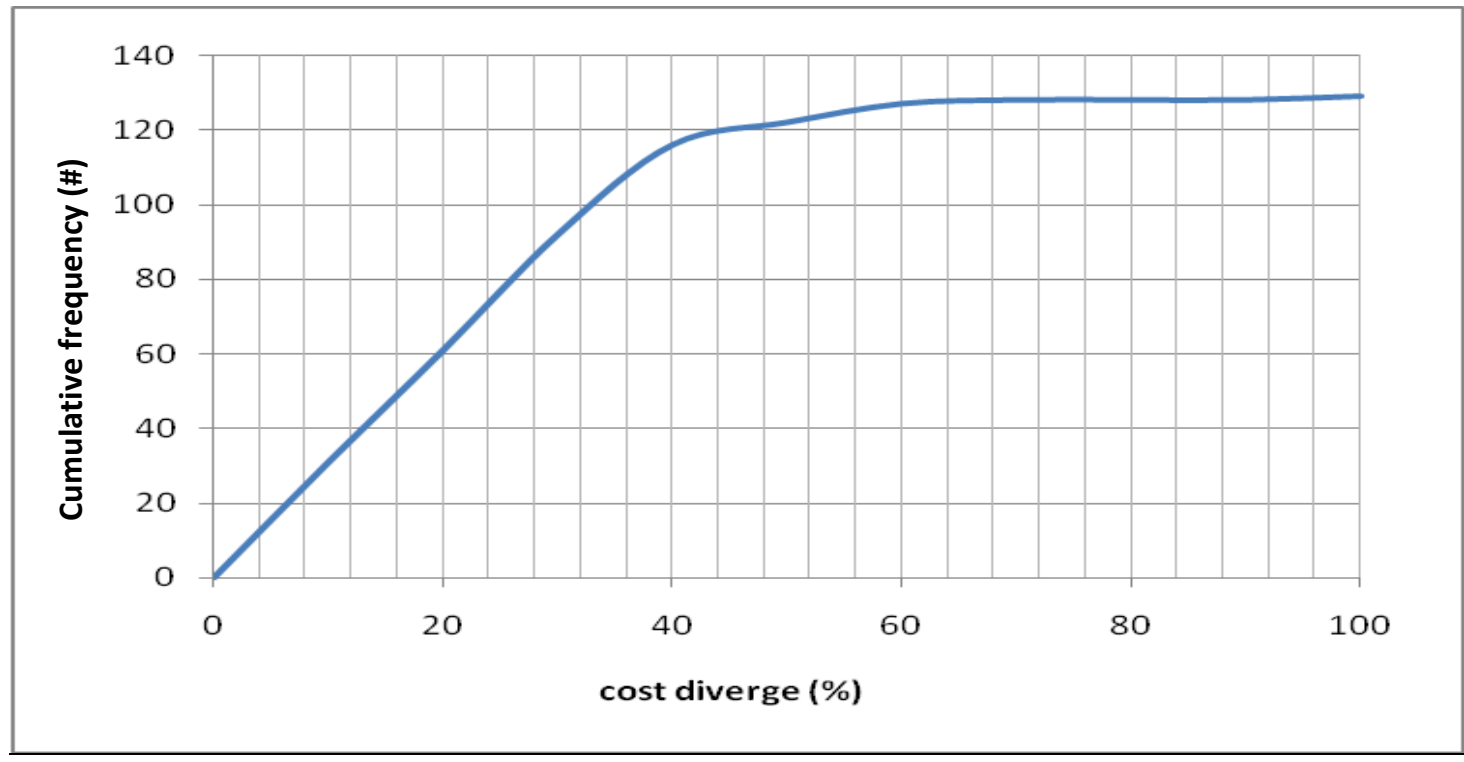

Figure $1 \mathrm{~S}$-curve of cost under estimation in road construction projects in the West Bank

Figure 2 The S-curve of cost over estimation on 40 road construction projects shows that:

- $57.5 \%$ of projects have actual cost less than estimated cost plus the allowable margin of $10 \%$.

- $42.5 \%$ of projects have cost over-estimates of between $10 \%$ and $40 \%$ 


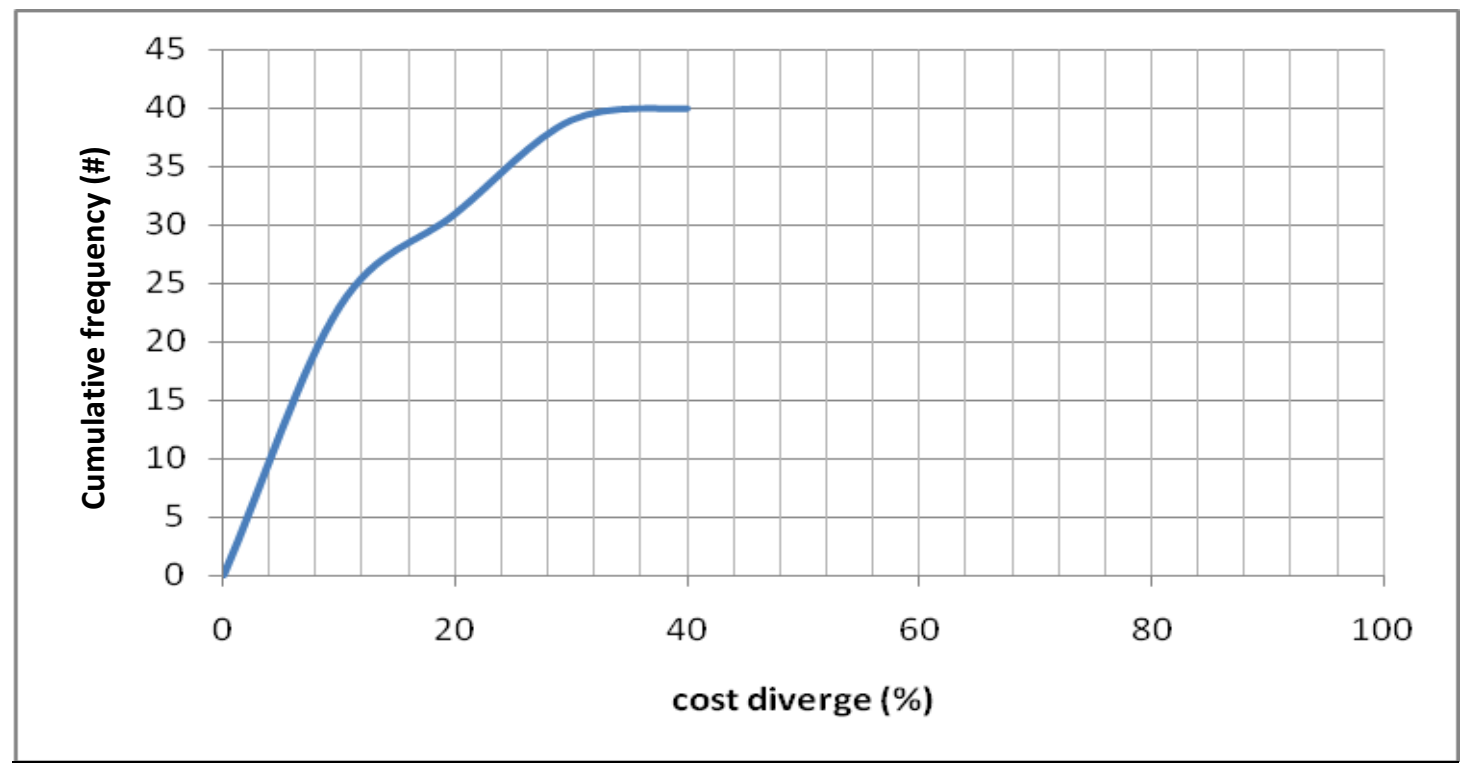

Figure 2 S-curve of cost overestimation in road construction projects in the West Bank

Figures 1 and 2 indicate that cost under estimation is more predominant than cost over estimation in road construction projects implemented in the West Bank.

\section{Cost Deviation vs. Project Size}

\section{Cost deviation in very small projects}

The cost deviation analysis of 20 very small projects shows that 11 projects have cost underestimates and 9 have cost over-estimates. The cost deviation average is $9.15 \%$ ranging from $-39.27 \%$ to $61.17 \%$. The following charts show the frequencies of cost over and under estimation in the total cost of very small road construction projects.

Figure 3 shows that the cost deviation in very small projects with cost under-estimates range between $0 \%$ to $40 \%$; and that $20 \%$ of the projects are within the allowable margin of $10 \%$ and that $80 \%$ have critical cost under estimation.

Figure 4 below shows that cost deviation in very small projects with cost over-estimates range from $0 \%$ to $40 \%$ and that $33 \%$ of project have cost over-estimates of less than $10 \%$ while $67 \%$ have cost over-estimates of more than $10 \%$.

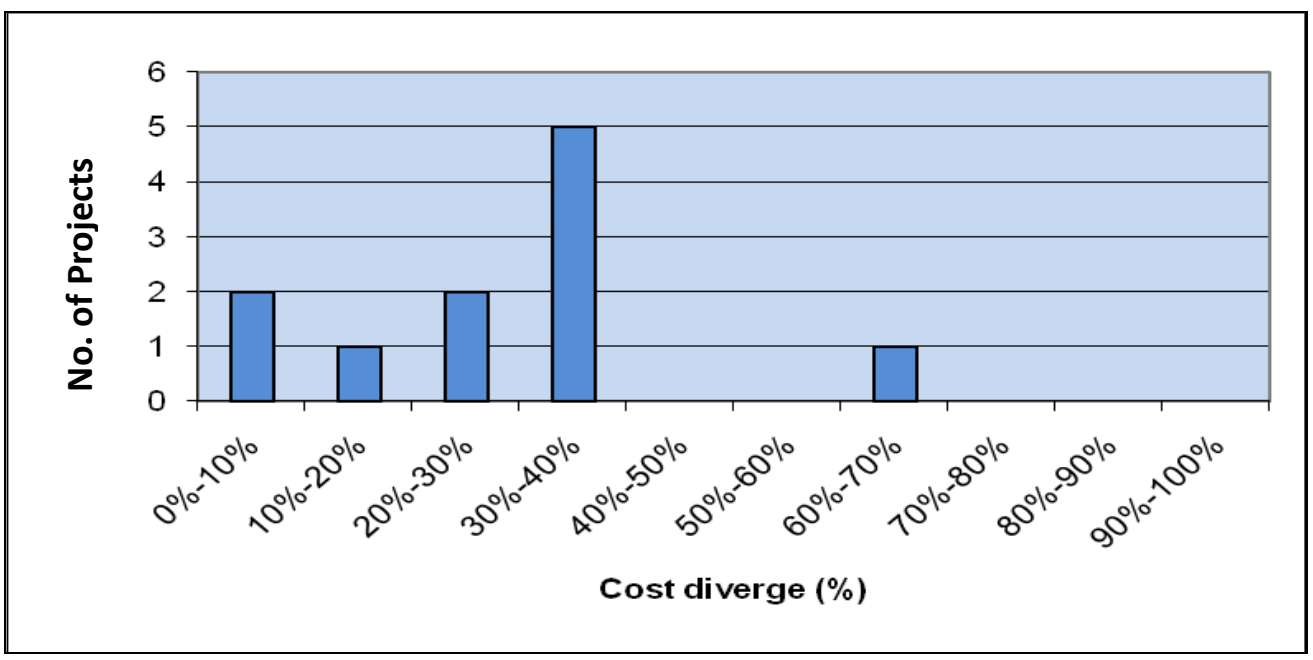

Figure 3 Cost under estimation vs. no of projects in very small road construction projects

Mahamid, I and Amund, B (2012) 'Cost deviation in road construction projects: the case of Palestine', Australasian Journal of Construction Economics and Building, 12 (1) 58-71 


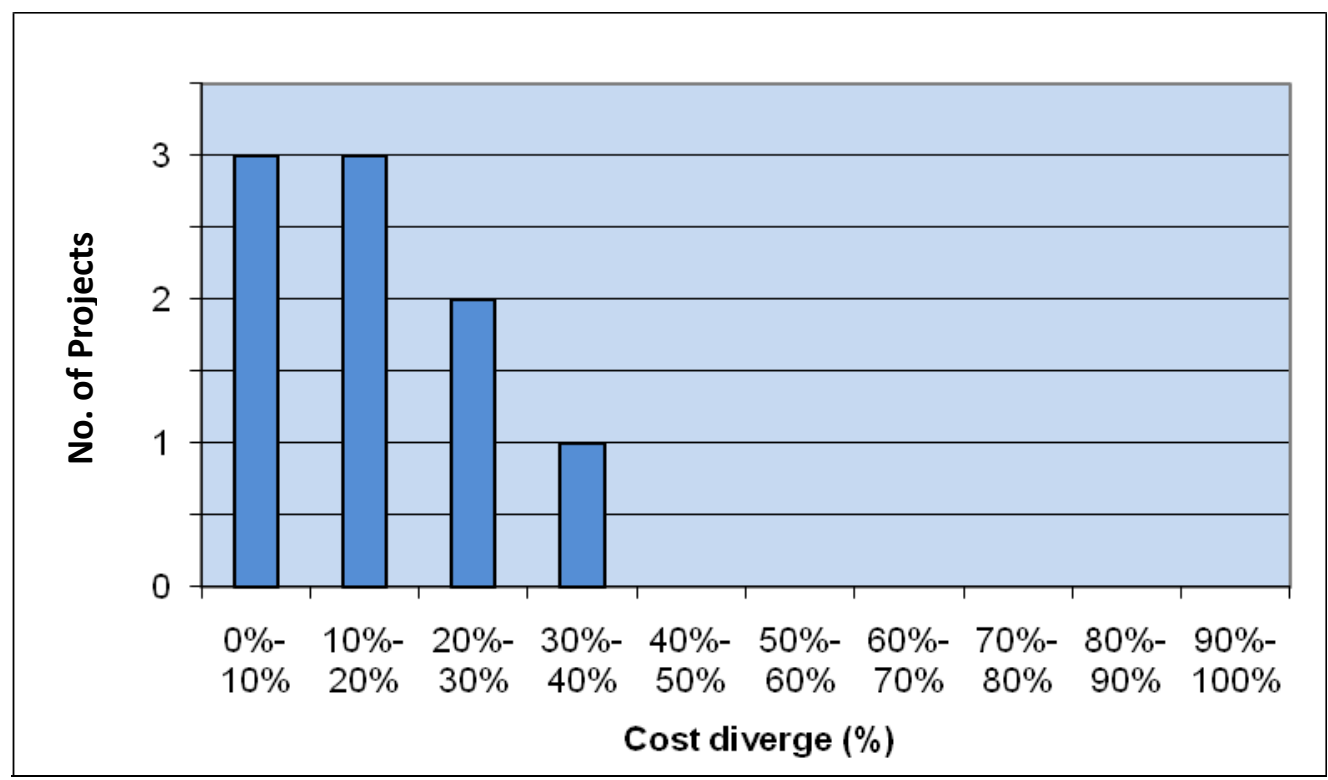

Figure 4 Cost over estimation vs. no of projects in very small road construction projects

The results from Figures 3 and 4 indicate that both cost over-estimates and under-estimates are frequent in very small construction projects constructed in the West Bank.

\section{Cost deviation in small projects}

The cost deviation analysis shows that of 46 small projects, 40 were under-estimated and 6 over-estimated. The cost deviation average is $22.78 \%$ ranging from $-28.99 \%$ to $98.04 \%$. Figure 5 shows the frequencies of cost over- and under-estimates in total cost of small road construction projects.

The frequency of small road construction projects with cost under-estimates indicates that:

- $10 \%$ of the projects were within the allowable margin of $10 \%$.

- $90 \%$ of the projects have cost under-estimates of more than $10 \%$.

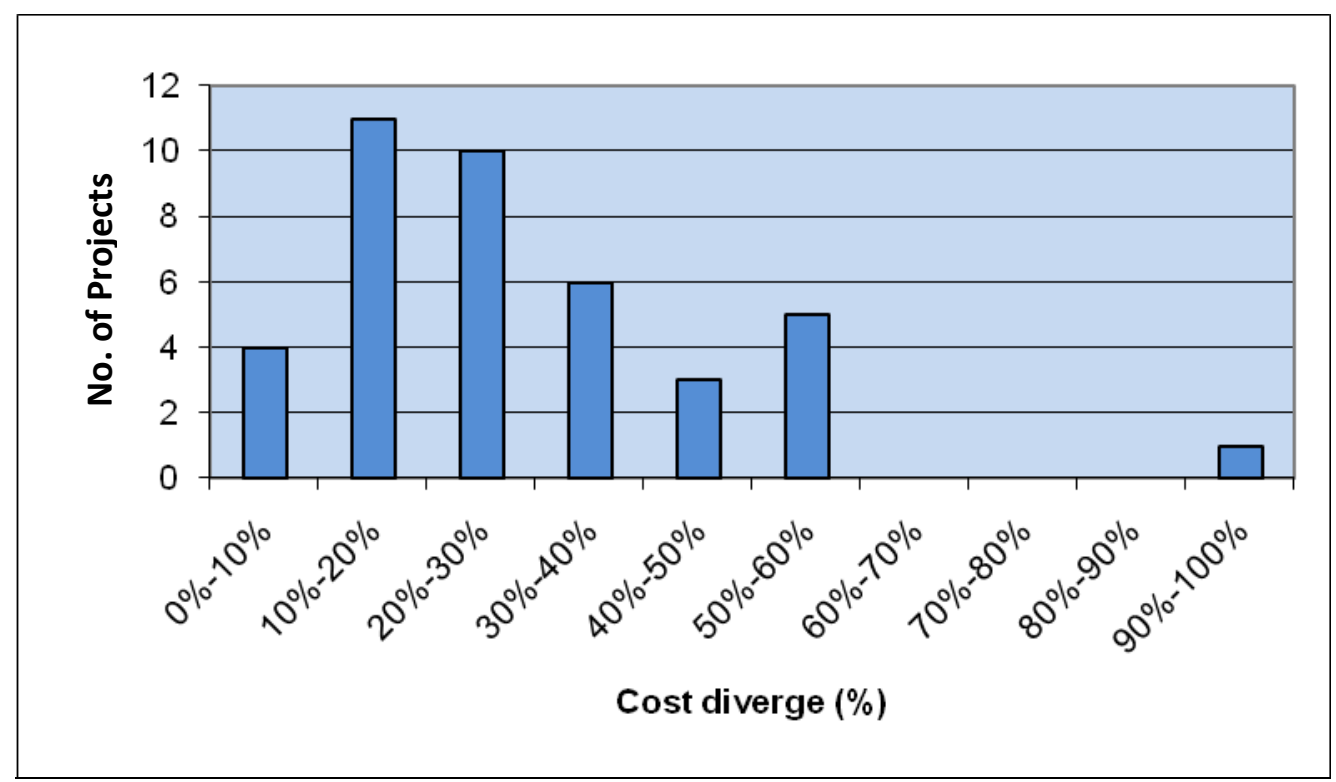

Figure 5 Cost under-estimates vs. no of projects in small road construction projects 
The frequency of small road construction projects with cost over-estimates (fig 6), indicates that:

- $50 \%$ of the projects are within the allowable margin of $10 \%$

- $50 \%$ of the projects have cost over estimation of more than $10 \%$.

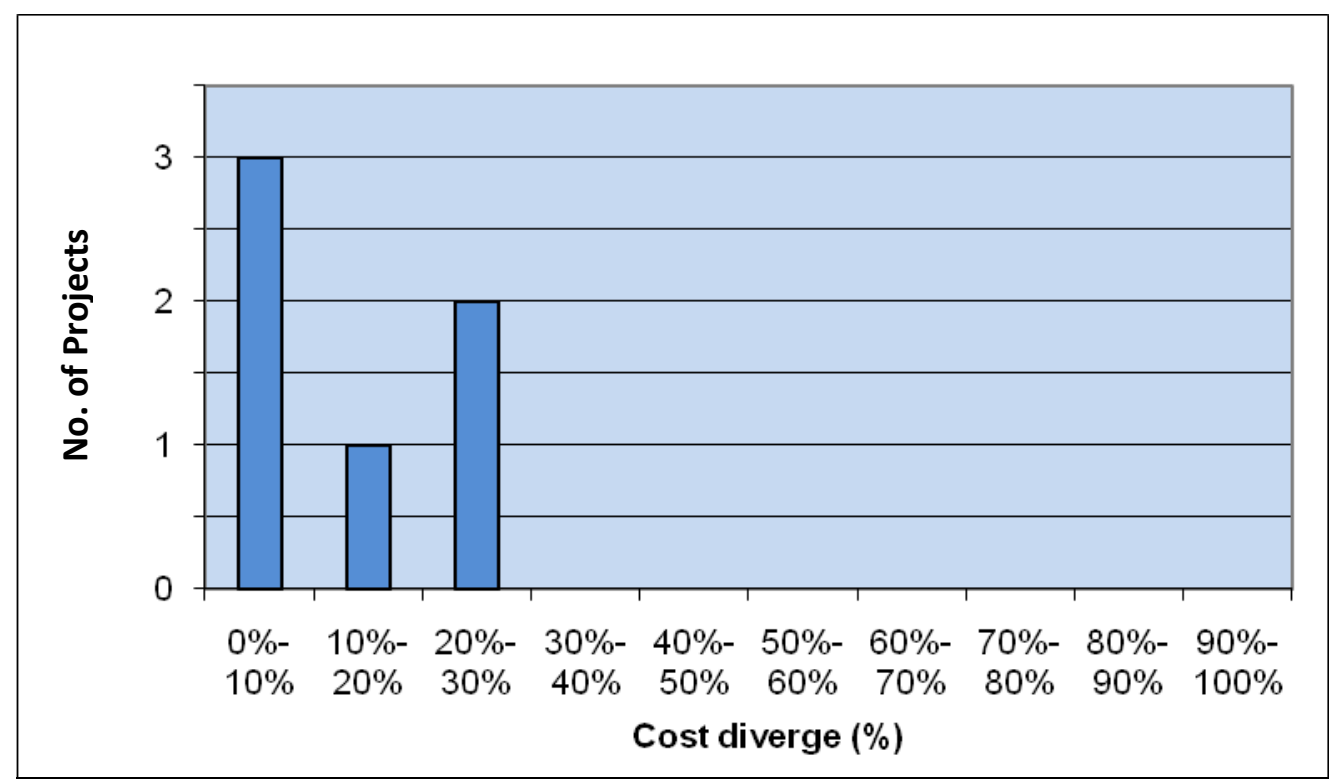

Figure 6 Cost over-estimates vs. no of projects for small road construction projects

The results from Figures 5 and 6 indicate that cost under-estimates are more common than cost over-estimates for small construction projects.

\section{Cost deviationin medium sized projects}

The cost deviation analysis for 48 small projects shows that 42 projects have cost underestimates and 6 projects have cost over-estimates. The cost deviation average is $17.67 \%$ ranging from $-11.63 \%$ to $43.53 \%$. The results are shown in charts 7 and 8 .

Figure 8 shows the frequency of medium road construction projects with cost under estimation, it indicates that:

- $25 \%$ of the projects are within the allowable margin of $10 \%$.

- $75 \%$ of the projects have cost under-estimates above $10 \%$.

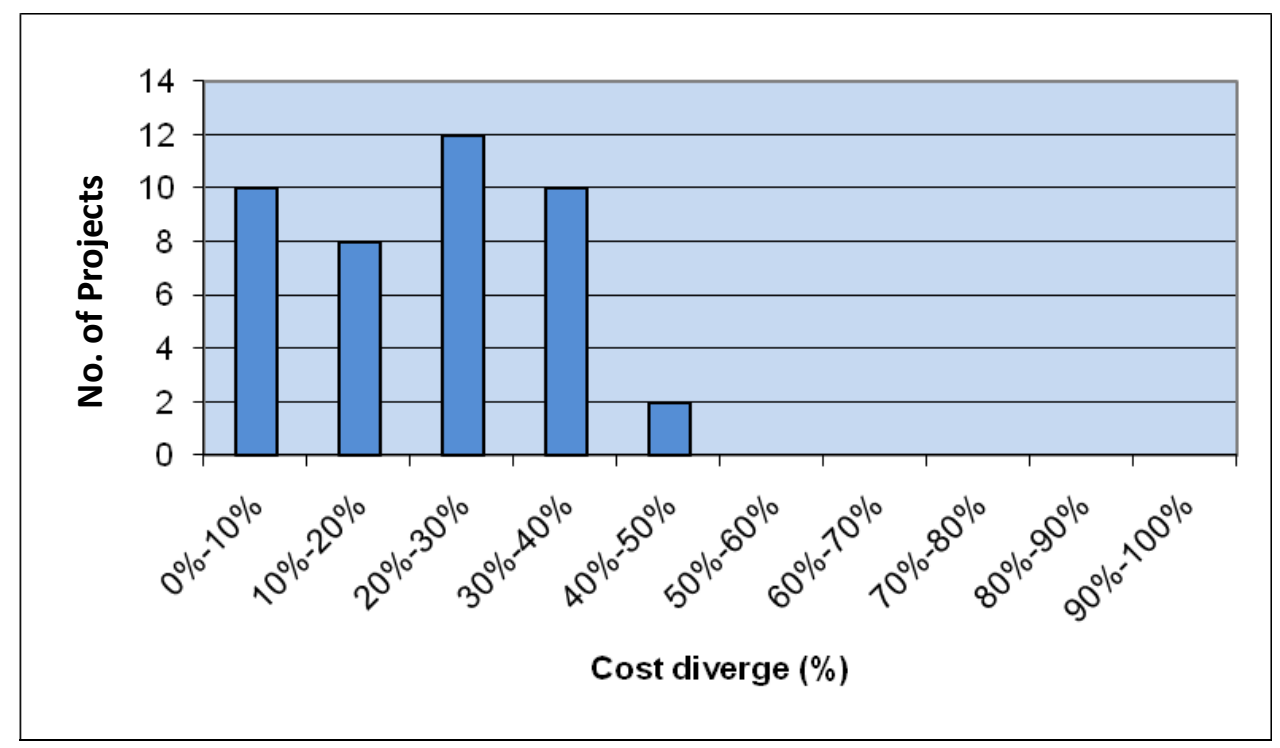

Figure 7 Cost under-estimates vs. no of projects in medium sized road construction projects

Mahamid, I and Amund, B (2012) 'Cost deviation in road construction projects: the case of Palestine', Australasian Journal of Construction Economics and Building, 12 (1) 58-71 
Figure 8 shows the frequency of medium road construction projects with cost over estimation, it indicates that:

- $83 \%$ of the projects are within the allowable margin of $10 \%$

- $17 \%$ of the projects have cost over-estimates above $10 \%$.

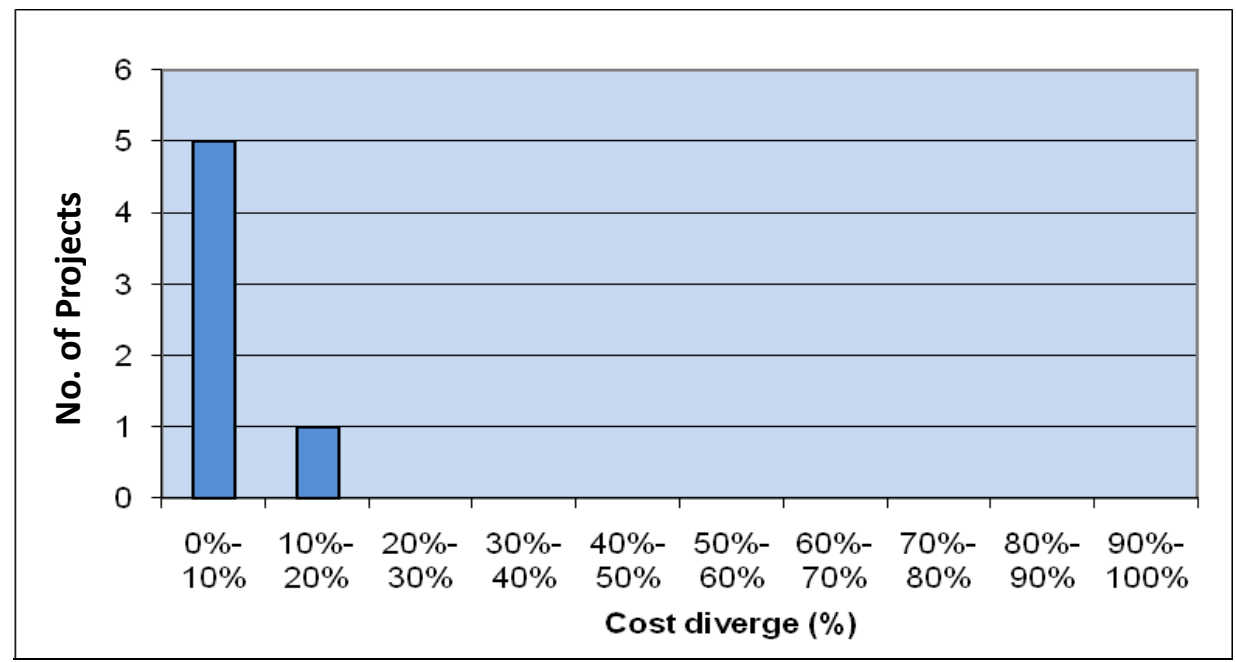

Figure 8 Cost over-estimates vs. no of projects in medium sized road construction projects

The findings of Figures 7 and 8 indicate that cost under-estimates are more common than cost over-estimates in medium sized construction projects. Most road construction projects in the West Bank are within this category, therefore the findings reflects the severity of problem of cost overruns.

\section{Cost deviation in large sized projects}

Data on 55 large projects show that 36 projects are under-estimated and 19 over-estimated. The cost deviation average is $6.94 \%$ ranging from $-25.91 \%$ to $49.92 \%$. The following charts show the frequencies of cost over and under estimation in large sized road construction projects.

Figure 9 shows the frequency of large road construction projects with cost under-estimates indicating that:

- $39 \%$ of the projects are within the allowable margin of $10 \%$

- $61 \%$ of the projects have cost under-estimates outside $10 \%$

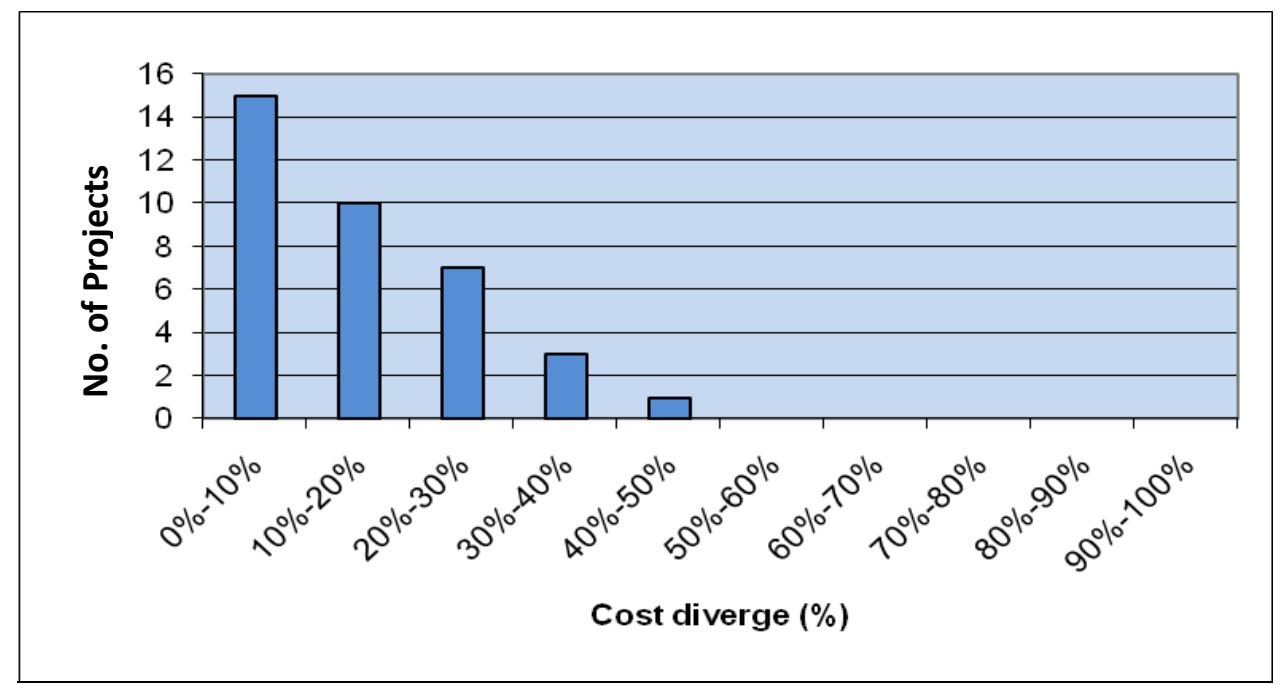

Figure 9 Cost under-estimates vs. no of projects in large sized road construction projects

Mahamid, I and Amund, B (2012) 'Cost deviation in road construction projects: the case of Palestine', Australasian Journal of Construction Economics and Building, 12 (1) 58-71 
Figure 10 shows the frequency of large sized road construction projects with cost overestimates, and indicates that:

- $63 \%$ of the projects are within allowable margin of $10 \%$ )

- $37 \%$ of the projects are outside this range.

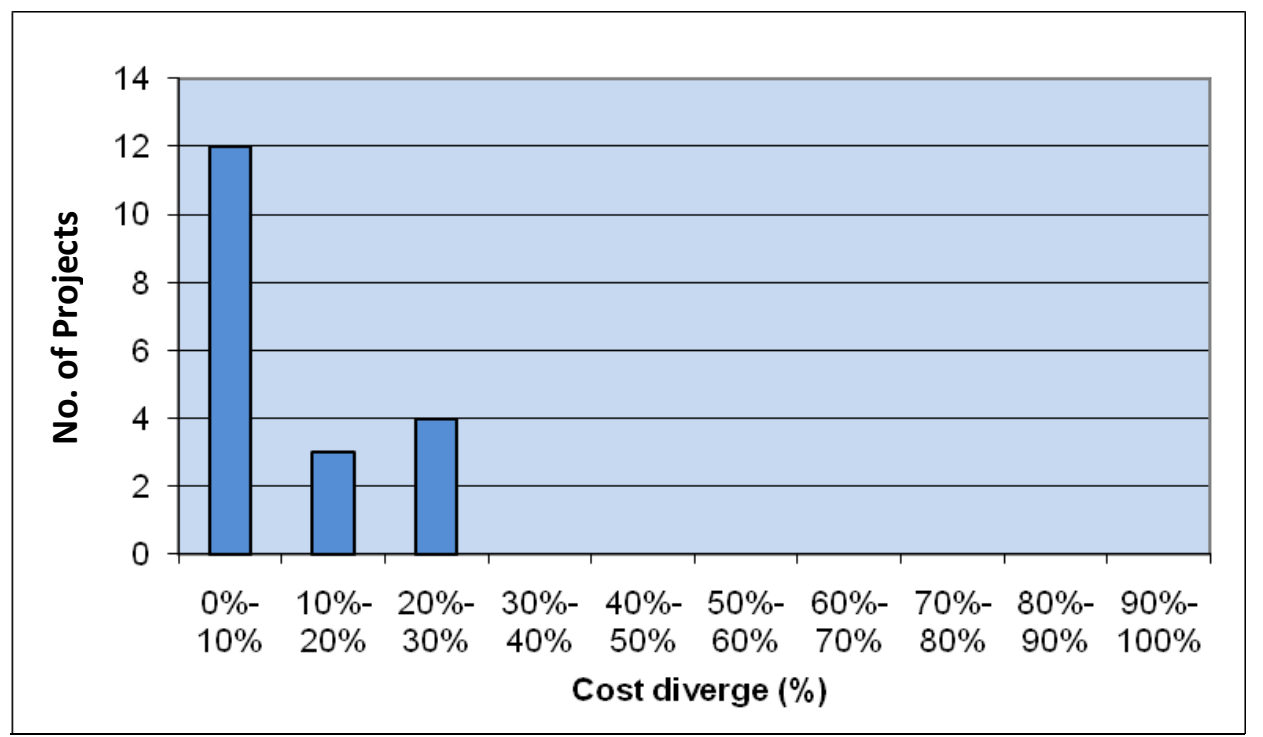

Figure 10 Cost over estimation vs. no of large sized road construction projects

The findings of Figures 9 and 10 indicate that for large sized construction projects cost under-estimates are more common than cost over-estimates. Given that the costs of such projects are greater than $\$ 300000$, the magnitude of the resulting additional costs in such projects is relatively high (i.e. $30 \%$ cost deviation equals at least $\$ 90000$ ). This makes the problem of cost deviation in road construction projects in the West Bank critical, since the Government (client of road construction projects) depends on very limited external funds to implement their projects.

\section{Regression Models Development}

Actual cost vs. estimated cost

A linear relation between estimated and actual cost of road construction projects can be shown in the following scatter gram.

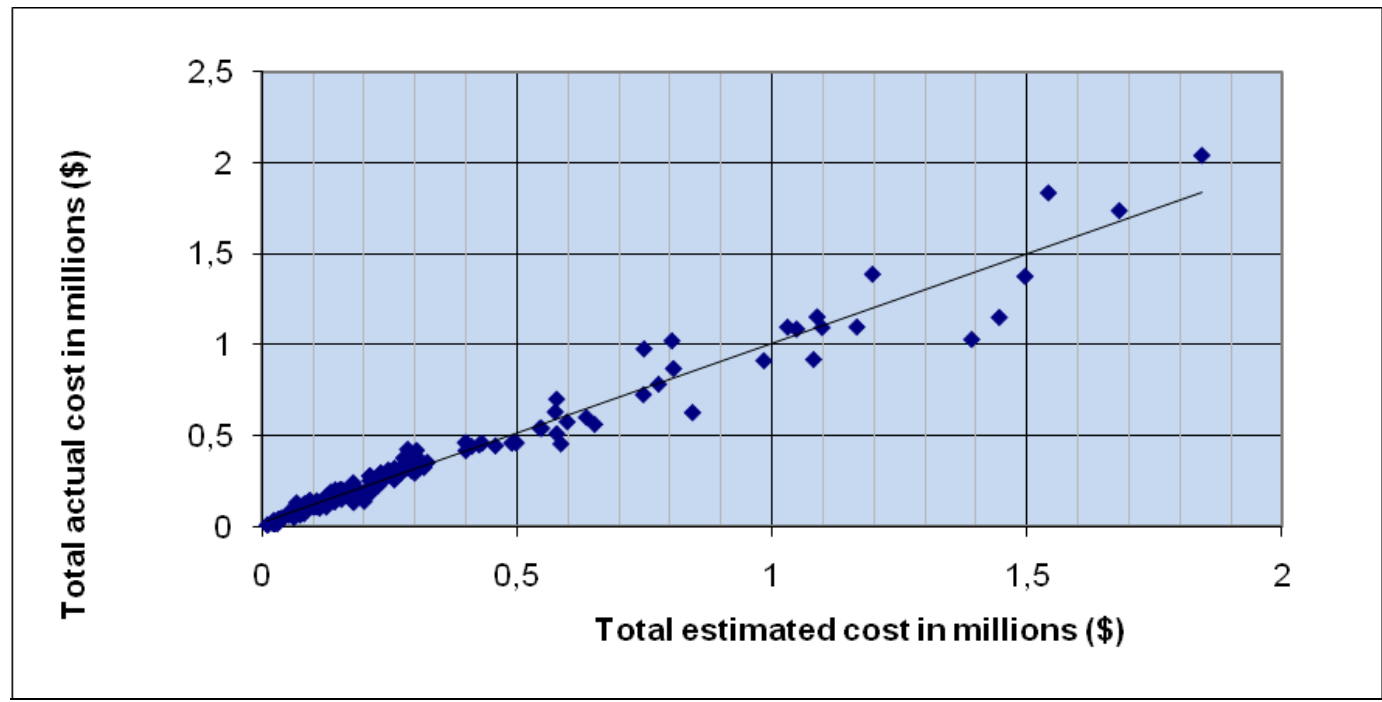

Figure 11 Actual cost vs. estimated cost in road construction projects

Mahamid, I and Amund, B (2012) 'Cost deviation in road construction projects: the case of Palestine', Australasian Journal of Construction Economics and Building, 12 (1) 58-71 
An equation that describes the relationship between actual and estimated costs is:

$$
\text { Actual cost }(\$)=25389.83+0.98 * \text { estimated cost }(\$)
$$

The following could be noted from this equation:

- The coefficient of determination R2 for the equation $=0.96$ as shown in Table 5 .

- The analysis of variance test confirmed the statistical significance of the model at a significance level of 0.05 as shown in Table 5

- The coefficient of estimated cost in the equation (0.98) meaning that the values of actual and estimated cost are close to each other

- The positive constant (25389.83) meaning that in general cost deviation in small projects is larger than it in large projects

\begin{tabular}{|c|c|c|c|c|}
\hline \multicolumn{2}{|c|}{ Regression Statistics } & & Coefficients & P-value \\
\hline Multiple R & 0,98 & Intercept & 25389,83 & 0,000290848 \\
\hline R Square & 0,96 & estimated cost & 0,982752 & $2,8412 \mathrm{E}-122$ \\
\hline Adjusted R Square & 0,96 & & & \\
\hline Observations & 169 & & & \\
\hline $\mathbf{F}$ & 4445,82 & & & \\
\hline
\end{tabular}

Table 5 Regression statistics of estimated cost vs. actual cost in road construction projects

To establish that the relative cost deviation in small projects is larger than it in large projects, two regression models are developed; one describing the actual cost as a function of estimated cost for all projects except the large ones (i.e. projects with actual cost $<\$ 300000$ ) and the other for projects of cost greater than $\$ 300000$, the results are:

$$
\begin{aligned}
& \text { Model for projects with cost }<\$ 300000 \text { is: Actual cost }(\$)=1.14 * \text { estimated cost }(\$) \\
& \text { Model for projects with cost }>\$ 300000 \text { is: Actual cost }(\$)=1.01 * \text { estimated cost }(\$)
\end{aligned}
$$

The coefficient of determination R2 is 0.98 for both models as shown in Table 6 and 7. Both models give better R2 when the intercept is set to zero. The coefficient of estimated cost in

\begin{tabular}{|c|c|c|c|c|}
\hline \multicolumn{2}{|c|}{ Regression Statistics } & & Coefficients & $P$-value \\
\hline Multiple R & 0,99 & Intercept & 0 & $\# N / A$ \\
\hline R Square & 0,98 & estimated cost & 1,142148 & 1,09E-96 \\
\hline Adjusted R Square & 0,97 & & & \\
\hline Observations & 114 & & & \\
\hline $\mathbf{F}$ & 5278,053 & & & \\
\hline
\end{tabular}
the first model is greater than it in the second one which means that the relative cost deviation tends to be larger in small projects.

Table 6 Regression statistics of estimated cost vs. actual cost in road projects with cost less than $\$ 300000$

\begin{tabular}{|l|c|l|l|c|c|}
\hline \multicolumn{2}{|c|}{ Regression Statistics } & & & Coefficients & P-value \\
\hline Multiple R & 0,99 & & Intercept & 0 & \#N/A \\
\hline R Square & 0,98 & & estimated cost & 1,010129 & $2,52 \mathrm{E}-47$ \\
\hline Adjusted R Square & 0,96 & & & \\
\cline { 1 - 1 } F & & & & \\
\hline Observations & 5592,42 & & & & \\
\hline
\end{tabular}

Table 7 Regression statistics of estimated cost vs. actual cost in road projects with cost more than $\$ 300000$

Mahamid, I and Amund, B (2012) 'Cost deviation in road construction projects: the case of Palestine', Australasian Journal of Construction Economics and Building, 12 (1) 58-71 


\section{Cost deviation vs. estimated cost}

A weak linear relation between cost deviation and estimated cost could be observed in the following chart.

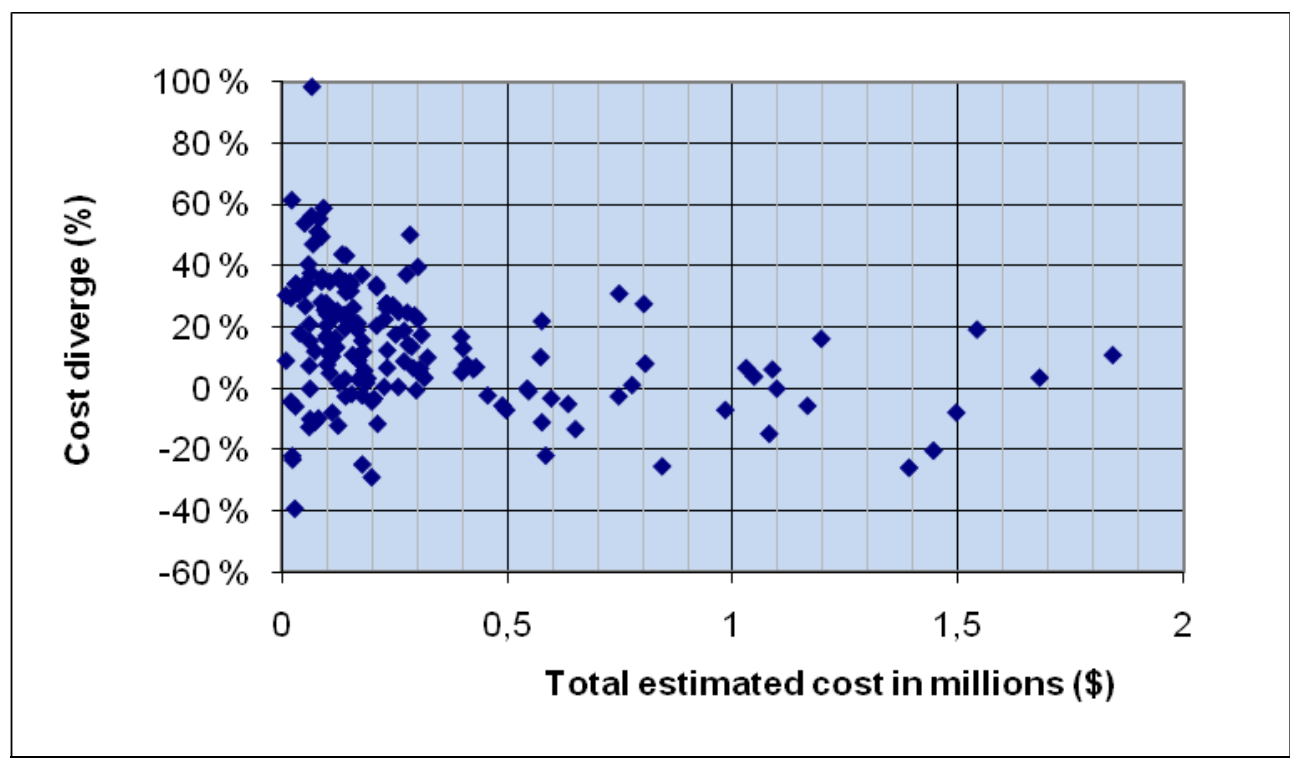

Figure 12 Cost deviation vs. estimated cost in road construction projects

A regression equation between relative cost deviation and estimated cost of road construction projects was estimated and the R2 (0.11) indicates a weak linear relation between them:

$$
\text { Cost deviation }(\%)=0.20-\left(1.9 * 10^{-7}\right) * \text { estimated cost }(\$)
$$

\section{Cost deviation vs. project size}

The regression analysis indicates that there is no linear relationship between cost deviation in road construction project and the project size (i.e. road length and width). The R2 is very low (0.0028). The following scatter gram shows the weakness of linear relation between cost deviation and project size.

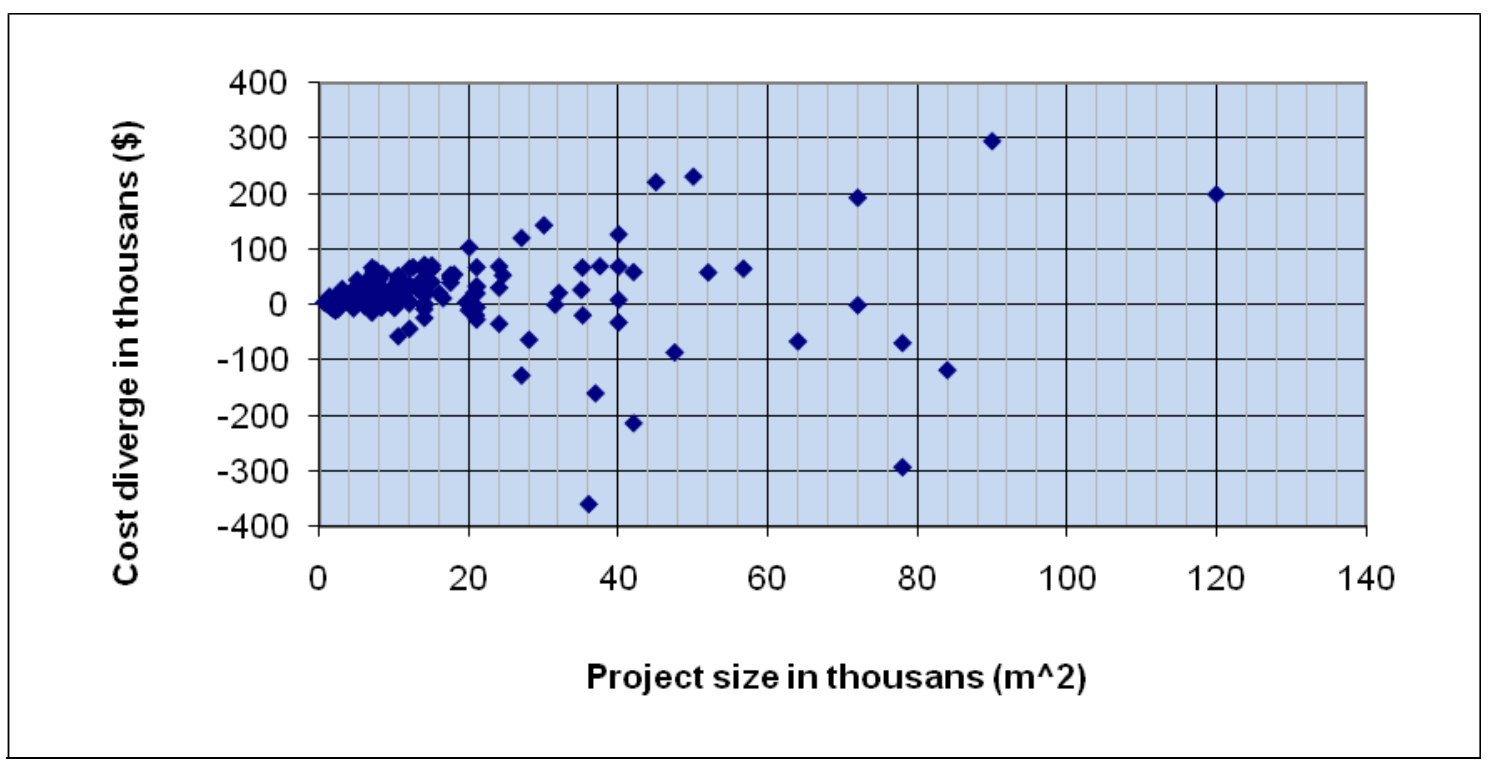

Figure 14 Cost deviation (\$) vs. project size in road construction projects 
In summary, the regression models that relate cost deviation in road construction projects and project size (i.e. road length and road width) reveal a weak linear relationship. This means that the cost deviation in road construction projects implemented in the West Bank is not systematic rather it seems caused by many factors that vary from project to project and site to site, but in total the findings reveal that cost deviation is a critical problem in road construction project in the West Bank.

\section{Conclusion}

This study has investigated the statistical relationship between actual and estimated cost of road construction projects using data from Palestinian road construction projects awarded over the years 2004 to 2008 . The study was based on a sample of 169 road construction projects. Based on this data several regression models were developed.

The findings reveal that all projects suffer from cost deviation, it is found that $76 \%$ of projects have cost under-estimates and $24 \%$ have cost over-estimates. The deviation between estimated and actual cost has an average of $14.6 \%$, ranging from $-39.3 \%$ to $98 \%$. These results agree with previous studies in that the cost deviation is predominant in road construction projects. The results show that cost under-estimates are more common than cost over-estimates in road construction projects implemented in the West Bank regardless the project category. Regression models that relate cost deviation in road construction projects and project size (i.e. road length and road width) reveal a very weak relationship.

\section{References}

Al-Khaldi, Z. (1990) Factors Affecting the Accuracy of Construction Costs Estimating in Saudi Arabia. Master thesis, King Fahd University of Petroleum and Minerals, Dhahran, Saudi Arabia

Al-Momani, A. (1996) 'Construction cost prediction for public school buildings in Jordan', Construction Management and Economics, 14, 311-317

Al-Zarooni, S. and Abdou, A. (2000) 'Risk management in pre-design stage and its potential benefits for UAE public projects', Proceedings of the 28th World Congress on Housing Challenges for the 21st Century, 15-19 April, Abu Dhabi, UAE

Amehl, O., Soyingbe, A. and Odusami, K. (2010) 'Significant factors causing cost overruns in telecommunication projects in Nigeria', Journal of Construction in Developing Countries, 15

Battaineh, H. (1999) Information system of progress evaluation of public projects in Jordan. Master thesis, Civil Engineering Dept., Jordan Univ. of Science and Technology, Irbid, Jordan

Flyvbjerg, B., Holm, M., and Buhl, S. (2003) 'Underestimating costs in public works projects, error or lie', Journal of the American Planning Association, 68 (3), 279-292

Jahren, C. and Ashe, A. (1990) 'Predictors of Cost-Overrun Rates', Journal of Construction Engineering and Management, 116 (3)

Mahamid, I. (2011) 'Analysis of Cost Deviations in Road Construction Activities: A Case Study from Palestine', Jordan Journal of Civil Engineering, 5 (4).

MAP (2002) Survey of the Construction Services Industry. Unpublished mission report. The West Bank and Gaza

Nega, F. (2008) Causes and effects of cost overrun on public building construction projects in Ethiopia. Master thesis, Addis Ababa University, Addis Ababa, Ethiopia

Odeck, J. (2004) 'Cost overruns in road construction-what are their sizes and determinants?', Transport Policy, 11, 43-53 
Omoregie, A and Radford, D. (2006) 'Infrastructure delays and cost escalation: causes and effects in Nigeria', Proceeding of sixth international postgraduate research conference, Delft University of Technology and TNO, 3-7 April, the Netherlands

Palestinian Economic Council for Development and Reconstruction (PECDAR), Personal communication, August, 2009. Ramallah, the West Bank, Palestine

Pickrell, D. (1990) Urban rail transit projects: forecasts versus actual ridership and cost. US Department of Transportation, Washington DC

Randolph, D., Rajandra, K., and Campfield, J. (1987) 'Using Risk Management Techniques to Control Construction Contract Costs', Journal of construction engineering and Management, 3 (4), 314-324

Rowland, H. (1981) The causes and effects of change orders on the construction process. Master thesis presented to the Georgia Institute of Technology, at Atlanta, Georgia, USA.

Skamris, M. and Flyvbjerg, B. (1996) 'Accuracy of traffic forecasts and cost estimates on large transportation projects', Transportation Research Record, p. 1518

Sodikov, Jamshid (2005) 'Cost Estimation of Highway Projects in Developing Country: Artificial Neural Network Approach', Journal of the Eastern Asia Society for Transportation Studies, 6, 1036 - 1047

Wilmot, C. and Cheng, G. (2003) 'Estimating Future Highway Construction Costs', Journal Construction Engineering and Management, 129 (3), 272-279

UNRWA (2006) Projects completion reports, UNRWA, Gaza 